\title{
Exploring Animal Models That Resemble Idiopathic Pulmonary Fibrosis
}

\begin{abstract}
Jun Tashiro', Gustavo A. Rubio', Andrew H. Limper ${ }^{2}$, Kurt Williams ${ }^{3}$, Sharon J. Elliot', loanna Ninou ${ }^{4}$, Vassilis Aidinis ${ }^{4}$, Argyrios Tzouvelekis ${ }^{4 \dagger}$ and Marilyn K. Glassberg ${ }^{1,5 * t}$

'Department of Surgery, University of Miami Miller School of Medicine, Miami, FL, United States, ${ }^{2}$ Department of Medicine, Mayo Clinic College of Medicine, Rochester, MN, United States, ${ }^{3}$ Department Pathobiology and Diagnostic Investigations, College of Veterinary Medicine, Michigan State University, East Lansing, MI, United States, ${ }^{4}$ Division of Immunology, Biomedical Sciences Research Center "Alexander Fleming", Athens, Greece, ${ }^{5}$ Department of Medicine, University of Miami Miller School of Medicine, Miami, FL, United States
\end{abstract}

Large multicenter clinical trials have led to two recently approved drugs for patients with idiopathic pulmonary fibrosis (IPF); yet, both of these therapies only slow disease progression and do not provide a definitive cure. Traditionally, preclinical trials have utilized mouse models of bleomycin (BLM)-induced pulmonary fibrosis-though several limitations prevent direct translation to human IPF. Spontaneous pulmonary fibrosis occurs in other animal species, including dogs, horses, donkeys, and cats. While the fibrotic lungs of these animals share many characteristics with lungs of patients with IPF, current veterinary classifications of fibrotic lung disease are not entirely equivalent. Additional studies that profile these examples of spontaneous fibroses in animals for similarities to human IPF should prove useful for both human and animal investigators. In the meantime, studies of BLM-induced fibrosis in aged male mice remain the most clinically relevant model for preclinical study for human IPF. Addressing issues such as time course of treatment, animal size and characteristics, clinically irrelevant treatment endpoints, and reproducibility of therapeutic outcomes will improve the current status of preclinical studies. Elucidating the mechanisms responsible for the development of fibrosis and disrepair associated with aging through a collaborative approach between researchers will promote the development of models that more accurately represent the realm of interstitial lung diseases in humans.

Keywords: bleomycin, idiopathic pulmonary fibrosis, murine model, asbestosis, aged mice

\section{BACKGROUND}

Idiopathic pulmonary fibrosis (IPF) is a devastating chronic lung disease, primarily affecting middle aged and older adults $(1,2)$. Lung function decline is gradual, with the potential for intermittent, unpredictable, acute exacerbations and the development of associated pulmonary hypertension (3). Disease diagnosis is primarily based on a typical radiology pattern (high-resolution computed tomography-HRCT) of usual interstitial pneumonia (UIP) characterized by reticulation and honeycomb cysts of subpleural and bibasilar distribution coupled with exclusion of other known causes of lung fibrosis as assessed by absence of exposures (occupational, environmental, drug), a negative immunologic profile and compatible bronchoalveolar lavage fluid (BALF) findings (i.e., absence 
TABLE 1 | Selected pulmonary fibrosis conditions in animal species.

Selected pulmonary fibrosis conditions in animal species

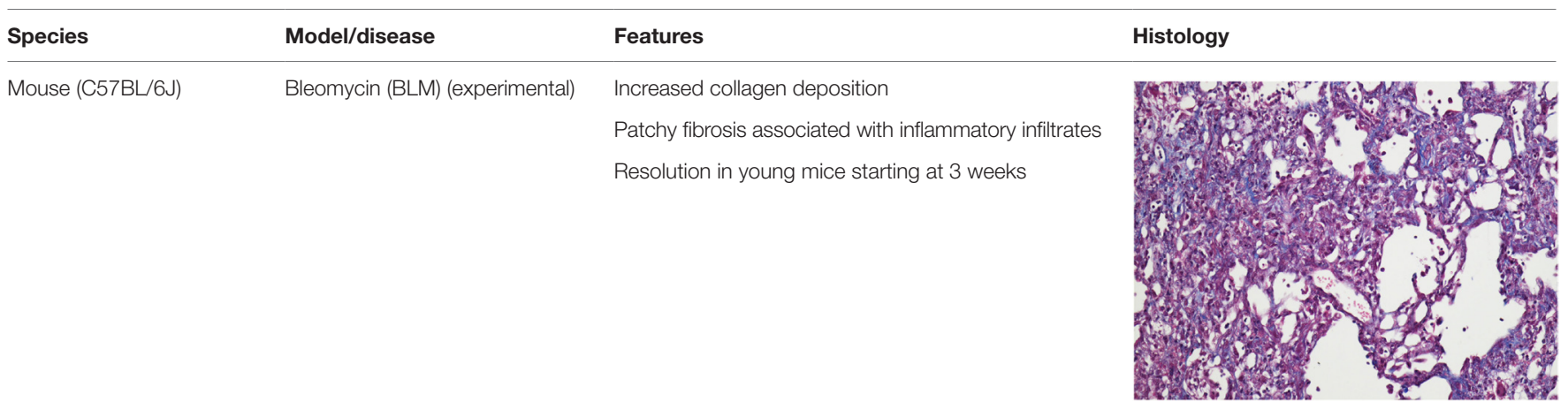

Dog (West Highland Terrier) Interstitial lung disease (ILD)

Septal widening and collagen deposition

Normal alveolar cells

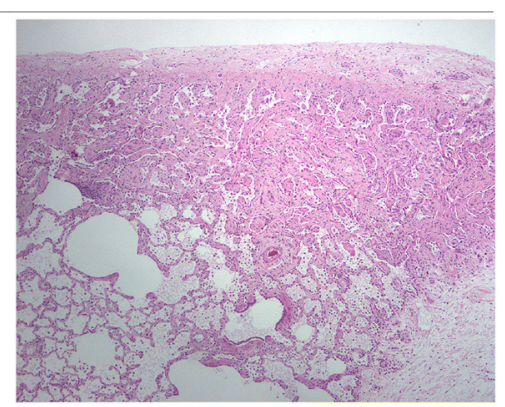

Associated with asinine herpesvirus 5 infection

Pleural, subpleural, and septal fibrosis extending to interstitium

Intra-alveolar fibrosis and alveolar septal elastosis

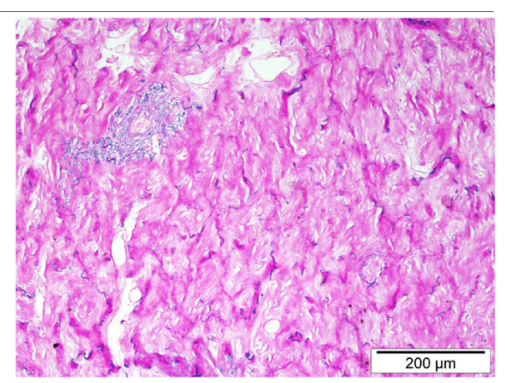

Horses
Equine multinodular pulmonary fibrosis
Associated with equine herpesvirus 5 infection

Multifocal coalescing nodules within parenchyma, centered on alveol

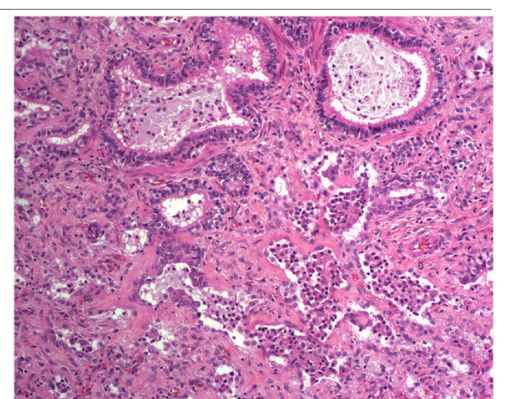

Cats

Idiopathic pulmonary fibrosis
Temporally heterogeneous fibrosis without inflammation

Patchy remodeling leading to honeycomb lung in late disease

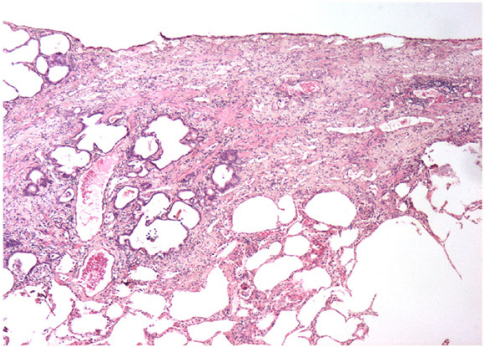

A variety of animal species exhibit pulmonary fibrosis conditions with characteristics similar to idiopathic pulmonary fibrosis (IPF) in humans. ILD has been studied as fibrosis occurs spontaneously in many animals, including West Highland Terriers, donkeys, cats, and horses. Mice have been used as experimental models with BLM-induced pulmonary fibrosis. Histologic images are provided at 10-20x magnification on Trichrome stain to display representative characteristics and similarities. Reproduced with permission, from Dr. Paul Mercer. Clin Sci (2015) 128:235-256, @ The Biochemical Society (97). 
TABLE 2 | Pros/cons of animal models for studying pulmonary fibrosis.

\begin{tabular}{|c|c|c|}
\hline Murine models & Pros & Cons \\
\hline Bleomycin & $\begin{array}{l}\text { Early molecular signature most similar to accelerated acute phase } \\
\text { of IPF in humans }\end{array}$ & Patchy, young mice resolve spontaneously unless repeatedly doses \\
\hline Silica & $\begin{array}{l}\text { Good model of lung injury in humans and persistence of fibrotic } \\
\text { lesions }\end{array}$ & $\begin{array}{l}\text { Lack of reproducibility, difficult delivery, prolonged time to fibrosis, } \\
\text { absence of usual interstitial pneumonia (UIP)-like lesions }\end{array}$ \\
\hline Asbestosis & Recapitulates asbestos exposure in human lung fibrosis & $\begin{array}{l}\text { Inhalation model requires at least a month for fibrosis to develop. } \\
\text { Single intratracheal dose leads to central fibrosis rather than } \\
\text { subpleural, unevenly distributed between lungs }\end{array}$ \\
\hline Cytokine overexpressing & $\begin{array}{l}\text { Ability to dissect downstream signaling events relevant to specific } \\
\text { fibrotic-inducing cytokines }\end{array}$ & $\begin{array}{l}\text { Models limited to dissecting specific pathways, rather than } \\
\text { recapitulating the complexity of human disease }\end{array}$ \\
\hline Fluorescent isothiocyanate & Relatively reproducible and persistent fibrotic phenotypes & $\begin{array}{l}\text { Lack representative UIP and inflammatory infiltrates preceding } \\
\text { fibrosis }\end{array}$ \\
\hline Radiation induced & Results in fibrosis, not pneumonitis if B6 mice are used & Need to wait a long time for development of fibrosis \\
\hline Familial models & Gave insight on telomere and telomerase gene involvement in IPF & May produce a susceptible phenotype, requiring a second hit \\
\hline Humanized (NOD/SCID mice) & $\begin{array}{l}\text { Can afford insight into role of different fibroblast populations, } \\
\text { dissects the contribution of epithelial-fibroblast crosstalk in the } \\
\text { absence of immune cells }\end{array}$ & $\begin{array}{l}\text { May not be representative of human disease where immune cells } \\
\text { play a role. Expensive and requires specialized housing }\end{array}$ \\
\hline Domestic animals & Pros & Cons \\
\hline Dogs & $\begin{array}{l}\text { Usually present in middle to old age. IPF in Westies shares some } \\
\text { features of human disease; foci with severe lesions, histological } \\
\text { criteria more typical for UIP may be present. Spontaneously } \\
\text { develop ILD }\end{array}$ & $\begin{array}{l}\text { The diffuse interstitial lesion, present in all affected Westies, } \\
\text { histologically resembles fibrotic NSIP in man }\end{array}$ \\
\hline Cats & $\begin{array}{l}\text { Anatomy of distal lung similar to humans. UIP-like disease. } \\
\text { Spontaneously develop ILD }\end{array}$ & Strain-dependent \\
\hline Donkeys & Spontaneously develop ILD & $\begin{array}{l}\text { Majority of cases of APF share key pathological features with human } \\
\text { pleuroparenchymal fibroelastosis not IPF }\end{array}$ \\
\hline Horses & $\begin{array}{l}\text { Spontaneously develop ILD. Overlapping features of pulmonary } \\
\text { fibrosis including weight loss and characteristic radiologic findings }\end{array}$ & Pathology not the same as IPF \\
\hline
\end{tabular}

of lymphocytosis). Hallmark features of UIP include epithelial cell hyperplasia, basement membrane denudation, honeycomb cysts, and accumulation of myofibroblasts foci in a pattern with regional and temporal heterogeneity (4).

Disease pathogenesis still remains elusive and controversial. Currently, the prevailing hypothesis assumes an ineffective wound healing response to alveolar epithelial cell injury $(5,6)$. Injury magnitude and susceptibility appears to be related to aging and genetic predisposition, with subsequent innate immune system and fibroblast activation $(3,5,7)$. The overall prognosis of patients with IPF is highly unpredictable and poor with median survival after diagnosis being approximately 3.8 years $(3,8,9)$. Attempts to understand disease pathogenesis, identify prognosticators, and unravel novel therapeutic targets (10-14) have relied on animal models. Unfortunately, no animal model fully recapitulates the histologic pattern of UIP or exhibits features of progressive disease. This, however, should not underestimate the fact that animal models are essential prerequisites for the subsequent application of prognostic tests and therapeutic interventions. Numerous clinical trials have been completed based on preclinical studies in animals and have led to the FDA approval of two drugs, pirfenidone and nintedanib $(15,16)$. Although these drugs slow disease progression, they do not cure $\operatorname{IPF}(5,17)$, thus at the best case leaving patients with significant pulmonary disability. Therefore, further studies in animal models that more closely mimic human IPF are needed to investigate potentially curative therapies. Although it is recognized that the spontaneous development of lung fibrosis in domestic animals (cats, dogs, etc.) can be informative, the most indispensable models for studies of pathogenesis and preclinical therapeutic assessment involve rodents. Many traditional and newly developed experimental models have provided us with valuable insights into disease pathogenesis and helped us to identify novel therapeutic targets to assess and validate in clinical trials (18-20). For a tabular representation of these models, see Table 1. This review aims to summarize current state of knowledge on animal modeling of lung fibrosis, mainly focusing on rodents, including environmental and genetic models, highlight limitations, and suggest future potentials.

\section{MURINE MODELS}

\section{Bleomycin (BLM)}

The model of BLM-induced lung fibrosis represents the most commonly applied experimental model. BLM is a chemotherapeutic antibiotic that has been identified as a pro-fibrotic agent when lymphoma patients developed pulmonary fibrosis after intravenous administration of BLM. It has been used in multiple species including mice, rats, guinea pigs, hamsters, dogs, and primates; yet, mice are most common (21). A sheep model is also currently under development (22). A recent ATS workshop report 
confirmed that there is a consensus view of the intratracheal BLM model as "the best-characterized animal model available for preclinical testing” (23).

\section{Mechanism of Action and Kinetics of Injury}

It is believed that BLM acts by causing single and double-strand DNA breaks in tumor cells and thereby interrupting cell cycle leading to apoptosis. BLM hydrolase, a BLM-inactivating enzyme, majorly affects drug effects on a tissue-specific basis. The lungs maintain low levels of the enzyme, as compared to liver, and therefore are more susceptible to BLM-induced injury. An overproduction of reactive oxygen species, due to chelation of metal ions and reaction of the formed pseudoenzyme with oxygen, leads to epithelial cell death (days 1-3), excessive inflammatory infiltrates (days 3-9, neutrophils found in the BALF at day 3 and lymphocytes at day 6), and ultimately to fibroblasts activation, extracellular matrix deposition, and development of fibrosis (days 10-21 with a peak around day 14), at the molecular (24-26) and histologic $(21,24,25,27)$ levels. Relative to IPF, it has been shown that the early molecular signature in mice is most similar to the accelerated acute phase of IPF in humans (28). Measurements of alveolar septal thickening, intra-alveolar fibrosis, increases in alveolar macrophages, and dilation of bronchioles and alveolar ducts demonstrated a rather uniform fibrotic state in a large sample size (29). Nevertheless, BLM-induced lung fibrosis has been severely criticized for not being representative of IPF due to the rapidity of its development, inflammation preceding fibrosis, and self-resolution nature usually after $21-28$ days following BLM challenge.

\section{Strains, Gender, and Age}

C57BL/6J mice have been the predominant animal model, as this particular strain is highly susceptible to lung injury following intratracheal BLM administration $(30,31)$. Conversely, the $\mathrm{BALB} / \mathrm{c}$ or SV129 strains confer resistance to BLM-induced pulmonary fibrosis, presumably due to alterations in transforming growth factor (TGF) $-\beta$ expression (31). This phenomenon parallels the experience in humans regarding genetic susceptibility and other potential risk factors for development of fibrosis in end organs following exposure to BLM. The majority of studies investigating BLM-induced pulmonary fibrosis to date have used young male mouse models, aged 8-12 weeks $(28,29,32)$. Young mice, however, have been shown to undergo spontaneous resolution of BLM-induced pulmonary fibrosis, a phenomenon not observed in aged mice $(24,33,34)$. Whether sex differences in mice parallel human IPF, which exhibits a tendency toward male predominance has not been fully determined. However, the use of aged male mice may provide a more clinically relevant model of IPF (33).

\section{Route of Delivery and Dose Regimens}

So far, BLM has been delivered by multiple methods including intratracheal, intraperitoneal, subcutaneous, intravenous, and inhalational. However, intratracheal is the most commonly route of administration $(21,24,26,28,29,32,35-39)$. It is believed that intratracheal administration better recapitulates the human phenotype that is limited to the lungs. However, it requires a surgical incision at the level of the trachea, and thus, it is associated with considerable peri-operative mortality. To this end, investigators are now applying the orotracheal route of delivery that exhibits similar kinetics of injury as intratracheal administration with significantly less side effects.

Another issue identified in studies using the BLM mouse model is the wide range of dosing regimens used (40). In mouse studies, weight-based dosing is most common, beginning at $1.25 \mathrm{U} / \mathrm{kg}(39)$ and up to a maximum of $4 \mathrm{U} / \mathrm{kg}(35,36)$. This dose is usually suspended in $50-100 \mu \mathrm{L}$ of phosphate-buffered saline for intratracheal instillation. Peng et al. performed BLM dose-escalation experiments with mortality rates of $19 \%$ with $3 \mathrm{U} / \mathrm{kg}$ and $50 \%$ with $5 \mathrm{U} / \mathrm{kg}$ (28). A slightly lower dose of 2.0-2.5 U/kg appears to provide the most effective model of lung fibrosis, while reducing sample loss due to high mortality. With regard to frequency of dosing, Degryse and colleagues directly addressed the issue of single versus repetitive dosing to model IPF using BLM-induced pulmonary fibrosis (24). Results from their investigation in young mice found that repetitive dosing of BLM promoted persistent fibrosis, evidenced by measures of hydroxyproline content and inflammatory cell infiltrates, in contrast to single dose experiments that demonstrated spontaneous resolution in young mice $(24,34)$. Most studies evaluating therapeutic interventions have not used repetitive dosing; rather, the use of a single dose of intratracheal BLM is usually followed shortly by administration of the therapy under investigation (35-38). Potential therapies are usually administered within 1-7 days following BLM exposure, leading to the conclusion that the therapeutic measures may provide benefit primarily through prevention of the inflammatory cascade rather than reversal of fibrosis, thus limiting their applicability to human IPF (40). More recent studies have begun to explore administration of drugs after 7 days $(41,42)$. To our knowledge, only two studies to date have evaluated repetitive BLM injury $(43,44)$. Lee et al. administered intratracheal BLM $(0.04 \mathrm{U})$ biweekly for a total of 4 months in young mice (43). They reported that in response to repeated BLM administration, mice developed hyperplasia of Club cells (Clara cells) and cuboidal alveolar epithelial cells, infiltration of the perialveolar ducts by inflammatory cells, septal thickening, enlarged alveoli, and extensive fibrosis (43).

\section{Silica}

Silica administration into murine lungs leads to the development of fibrotic nodules that resemble lesions that develop in humans following exposure to mineral fibers and particulate aerosols (45). Silica delivery presents with many variations including aerosolization, intratracheal, or orotracheal instillation (46-50). The fibrotic response is strain dependent with C57BL/6 mice found to be more susceptible than CBA/J mice after intratracheal delivery of silica fibers. Nodules develop around silica deposits and silica fibers are easily identified both by histology and polarization microscopy (47). The fibrotic response is associated with limited inflammation and enhanced fibrotic lesions mediated by increased production of pro-fibrotic growth factors and cytokines including PDGF, TGF- $\beta$, TNFa, and IL-10 (51-53). Kinetics of injury is highly heterogeneous and dependent upon route of administration, dose regimens, and formulations of 
silica particles (45). In particular, intratracheal models are easier, shorter (fibrosis develops within 14-28 days), and costefficient, while aerosolized route of delivery takes longer to produce fibrotic lesions (40-120 days) (45). Heating preparation procedures before instillation are mandatory in order to inactivate any trace endotoxin (45). The greatest advantage of the silica model of lung fibrosis is the persistence of fibrotic lesions due to diminished clearance of silica particles from the lungs $(51,52,54)$. However, the model presents with major caveats including problematic and highly expensive equipment for aerosolized delivery, prolonged waiting periods until development of fibrosis (4-16 weeks), lack of reproducibility of fibrotic pattern, and absence of characteristic UIP-like lesions such as fibroblastic foci, regional heterogeneity, and hyperplastic epithelium. These have severely limited its widespread applicability in the preclinical setting (20).

\section{Asbestosis}

Another model that recapitulates an important form of human lung fibrosis is that of asbestos exposure. Asbestos-induced model of lung fibrosis is clearly distinguished from IPF by several histologic findings including asbestos bodies embedded within the fibrous tissue, fewer myofibroblasts foci and bronchial wall fibrosis. In some cases, the pattern of UIP can be also present $(55,56)$. Some of these features are recapitulated in inhalation models in animals and have helped us understand the pathogenesis of both asbestosis and IPF (57-61). A single intratracheal administration of asbestos fibers mediates development of fibrosis; however, the model presents with several caveats since fibrosis that tends to be central rather than subpleural and is quite often unevenly distributed between lungs. Inhalation models develop a more peripheral pattern; yet, disease development can be prolonged, especially if using chrysotile fibers. The intratracheal animal models with amphibole fibers follow the kinetics of BLM models, with fibrosis development at day 7 and peak at day 14. Inhalation models may take up to a month for establishment of fibrotic injuries. Mechanistically, the deposition of asbestos fibers triggers fibrosis through alveolar epithelial cell apoptosis, M2 polarization of macrophages, and overproduction of pro-fibrotic cytokines by activated T lymphocytes, all events leading to myofibroblast differentiation and extracellular matrix production (57-61).

\section{Age-Related Models}

IPF is an age-related disease paradigm, and more recently, it has been proposed that many of the hallmarks of aging including genomic instability, telomere attrition, epigenetic alterations, deregulated cellular bioenergetics, and cellular senescence, can be considered characteristics of the fibrotic lung (62-64). Studies have shown that older mice are more susceptible than younger mice to pro-fibrotic stimuli including BLM (26). This is of particular interest given that IPF is predominant in older individuals. Transgenic deletion of senescence-related genes including RAGE, and relaxin has been associated with spontaneous age-dependent development of lung fibrosis indicating the cardinal role of aging in disease susceptibility (65-67). On the other hand, the role of "virome" as a pro-fibrotic mediator has been further dissected in the context of aged-related development of lung fibrosis by demonstrating that only aged mice ( $>15$ months) develop $\gamma$-herpesvirus-68-induced lung fibrosis through a mechanism that involved alveolar epithelial cell reprogramming to produce pro-fibrotic factors and enhanced TGF- $\beta$ signaling in lung fibroblasts (68). In addition, Torres-Gonzalez et al. (69) reported that aging mice receiving gamma herpesvirus responded with endoplasmic reticulum stress, apoptosis of type II lung epithelial cells, and activation of profibrotic pathways.

This evidence could be reminiscent to the presence of herpes viral genomes within IPF lungs and the epidemiological association between viral infections and IPF acute exacerbations (70).

\section{Cytokine Overexpression}

During the past two decades, more sophisticated and advanced methods have been widely used to study the features of lung fibrosis on an experimental setting. Both gene transfer via adenoviral or lentiviral vectors and transgenic approaches have been used to overexpress pro-fibrotic cytokines including TGF- $\beta$, TNF- $\alpha$, IL-1 $\beta$, and IL-13 and promote fibrotic phenotypes by dissecting downstream signaling pathways that are highly relevant to human lung fibrosis (71-73). The overexpression of TGF- $\beta$ can be produced via adenoviral intranasal delivery or doxycycline-induced transgenic overexpression in CC-10-positive lung epithelial cells. Both models are strain dependent with C57BL/6 mice being more susceptible that BALB/c. In the doxycycline-inducible Clara cell (CC10)-promoter driven model of TGF- $\beta$-induced lung fibrosis, addition of doxycycline to the water of animals leads to release of the tetracycline-controlled transcriptional suppressor allowing the reverse tetracycline transactivator to bind to the transgene (TGF- $\beta$ ) and promote its acute expression even $12 \mathrm{~h}$ after treatment with doxycycline (74). That leads to alveolar epithelial apoptosis and myofibroblast accumulation leading to airway and parenchymal fibrotic response starting at day 7 and peaking at days 14-21. Fibrosis may persist and progress over the duration of doxycycline exposure for up to 2 months (74). Similar kinetics are also observed with adenoviral delivery of TGF- $\beta$ through the intranasal route leading to epithelial cell apoptosis (day 1), mononuclear cell infiltration (days 3-7), and fibrotic scarring that tends to be more persistent than those produced by BLM exposure and thus tend to mimic better human disease features (71). Nevertheless, both models quite often produce highly variable and heterogeneous kinetics of injury with regards to severity and extent of lesions and lack of major reproducibility. A similar concept has been also applied for adenoviral-mediated gene transfer of IL-1 $\beta(75)$ and TNF- $\alpha(76,77)$ or lung-specific transgenic overexpression of IL-13 (78), thereby resulting in an early inflammatory response and later collagen deposition through activation of TGF- $\beta$ signaling pathway. Nonetheless, these models are not well established and thus can only be used to dissect relevant pathogenic pathways and not on a general basis to recapitulate the complexity of human disease.

\section{Other Models}

Fluorescent isothiocyanate (FITC) is another chemical compound used to induce experimental lung fibrosis (79). Fluorescein acts as a hapten and binds to airway proteins, thus 
acting as a depot for prolonged exposure to the injurious stimulus leading to fibrotic responses within 2-4 weeks that persist up to 24 weeks $(79,80)$. The model produces relatively reproducible and persistent fibrotic phenotypes in both BALB/c and C57BL/6 mice. Disadvantages include absence of representative UIP findings and predominant inflammatory infiltrates that precede fibrosis (80). The model is mostly dependent on Th2 cytokines (IL-13) and was seminally discovered to explore the relationship between the chemokine signaling receptor 2 (CCR2) and its ligand CCL12 for recruitment of fibrocytes during progression of fibrosis (81). It offers the advantage of easily trackable fluorescence-labeled fibrotic tissues. Nevertheless, model robustness is largely dependent on technical issues that are highly variable including the batch of FITC and the size of the particles formulated through sonication (20). Smaller particle sizes due to prolonged sonication may lead to acute toxicity and death (20). Finally and most important, FITC is an artificial chemical compound with limited human relevance since this type of injurious stimulus has never been described in humans (20).

Radiation-induced fibrosis represents a human relevant injury that leads to development of fibrosis which is strain dependent (C57BL/6 are the most susceptible) and can be local or systemic if other organs are not shielded (82-87). It is a relatively slow procedure that results in mature fibrosis after 24 weeks; yet, fibrosis is majorly dependent on inflammation and free-radical-mediated DNA damage and less on TGF- $\beta$ (84).

Familial models of IPF have been also used to study the contribution of the disease genetic background that significantly altered our perspective regarding disease pathogenesis and treatment response. Mice with targeted deletion of shelterin, a six-protein complex that binds and preserves telomeric repeats, from type alveolar epithelial cells, have been shown to develop spontaneous fibrosis $(88,89)$.

Mutations in the telomere and telomerase genes have been associated with familial IPF (90). Telomere dysfunction results in alveolar epithelial stem cell senescence, which is sufficient to drive lung remodeling and recruit inflammation. Telomerase reverse transcriptase has been reported to be transiently increased in BLM, hypoxic, or silica-induced lung injury (91-93). On the other hand, telomerase-deficient mice, despite significant telomere shortening, did not present with enhanced BLM-induced fibrotic responses (94).

Although mutations resulting in SP-C deficiencies are linked to a small subset of spontaneous and familial cases of interstitial lung disease (ILD) and interstitial pulmonary fibrosis $(95,96)$, SP-C-deficient mice do not fully recapitulate familial interstitial pulmonary fibrosis (97) as they develop mild ILD and an emphysematous phenotype. It is more than evident that these mutations may generate a susceptible phenotype; yet, a second hit of environmental origin is needful to partially recapitulate human phenotype.

Finally, humanized models of lung fibrosis involving the intravenous instillation of human IPF lung fibroblasts into immunodeficient non-obese diabetic mice (NOD/SCID) have recently garnered much attention (98-100). This model allows for cell trafficking during different stages of fibrosis development and progression, offers unique insights into different fibroblast populations that reflect IPF heterogeneity, and dissects the contribution of epithelial-fibroblast crosstalk into the disease pathogenesis considering the absence of immune cells (99). Nevertheless, the latter is not representative of human disease where immune cells appear to play cardinal role. Another major disadvantage that limits its widespread applicability is the high cost and the specialized housing that is required (101). The use of animals with humanized immune system may also provide unique insights and fully recapitulate features of IPF (101).

\section{DOMESTIC ANIMALS}

The field of comparative oncology has set the stage for collaborations that utilize spontaneous models of progressive fibrotic lung diseases of mutual interest to veterinary and human medicine. The results of these kinds of studies promise to enhance the understanding of common factors important to disease development in a variety of species and to refine treatments for both humans and animals. Moreover, they may provide insights into unanswered questions involving naturally occurring models of pulmonary fibrosis.

In contrast to the six million dogs and cats that develop cancers, the incidence and prevalence of pulmonary fibrosis in animals is not known (102). West Highland Terriers (Westies), cats, donkeys, and horses develop ILD (102-107). There is limited information on the spectrum of clinical parameters (e.g., radiology) and pathology of these lung diseases leading to the classification of "idiopathic pulmonary fibrosis" being applied to such cases, without using the same strict clinical criteria that have been developed for human IPF. Recent evidence suggests that in contrast to IPF in humans, applying the term "idiopathic" in animals may be premature because of more non-specific features in lung interstitial disease in animals. The American Thoracic Society/European Respiratory Society definition of IPF incorporates histology, radiographic, and clinical course in the definition and the exclusion of other known causes of ILD, including environmental exposures, connective tissue disease, and drug toxicity (108). Further studies using multidisciplinary classification of veterinary lung disease to better characterize the disease in animals will help to define their relation to human disease and their potential role as models to develop treatments for both human and veterinary medical practice.

A study on Westies (109) found that the majority of dogs with IPF showed multifocal areas of accentuated subpleural and peribronchiolar fibrosis with occasional "honeycombing" and profound alveolar epithelial changes, reminiscent of human UIP and not commonly seen in NSIP. Interstitial fibroblastic foci, characteristic of UIP, were not seen in WHWTs with IPF. Progressive fibrosis, with intra-alveolar organizing fibrosis alongside interstitial mature collagen deposition, was present within the more severely affected areas of lung in WHWTs with IPF. Severe pulmonary lesions were seen more commonly in the caudal than in the cranial lung lobes.

A more recent study correlating CT scans and course of disease in Westies found a generalized ground-glass pattern was determined to be a sign of a mild form of canine idiopathic pulmonary fibrosis, whereas mosaic ground-glass and mild 
honeycombing patterns was identified in moderate and severe forms of the disease (110).

The ubiquitous gammaherpesvirus equine herpesvirus 5 (EHV 5) has been detected in lung tissue from horses that develop progressive pulmonary fibrosis and is now considered to be the likely cause of this disease in these animals (111). The pathology of this disease is distinct from human IPF, demonstrating multiple nodules and is therefore termed equine multinodular pulmonary fibrosis (111). Although the pathology is not the same as IPF, there are striking overlapping features including weight loss and gradual exercise intolerance, accompanied by characteristic radiologic features (111). Temporal heterogeneity or fibroblast foci, hallmarks of human disease, are not present in the disease in horses, though these characteristics have been described in feline pulmonary fibrosis $(111,112)$. Similar to EBV in humans, which has been associated with IPF, EHV 5 is a ubiquitous subclinical gammaherpesviral infection in horses (113). Considered largely non-pathogenic in the natural host, some strains of EHV5 appear to be pathogenic and capable of inducing lung fibrosis (103). While EHV5 was isolated from horses with spontaneous disease, the virus was not isolated from dead inoculated horses that developed lung fibrosis (111). This model raises interesting questions regarding induction of lung fibrosis by EHV 5 during viral latency versus lytic infection.

For a tabular representation of the overall advantages and disadvantages of each model, see Table 2.

\section{Read-Out Assays for Assessment of Fibrotic Injury}

Each experimental model presents with its own kinetics of fibrotic injury; however, investigators have applied standard operating procedures for reproducible evaluations of lung fibrosis. In view of the pathologic hallmarks of IPF, appropriate read-out assays include assessment of collagen deposition, alveolar epithelial cell apoptosis, and BALF complemented by survival analysis and respiratory mechanics. These are achieved with the following modalities: (1) histological analysis with Masson trichrome and $\mathrm{H} \& \mathrm{E}$ staining coupled with Aschroft score that quantifies extent of fibrotic changes, (2) hydroxyproline or total collagen content for quantification of lung collagen deposition, (3) TUNEL assay for the identification of apoptotic cells, (4) BALF analysis to assess changes in differential cell count and levels of inflammatory and fibrotic markers, (5) survival analysis with Kaplan-Meier plots, (6) in vivo lung function measurements (elastance and compliance) using the Flexi-vent ventilator, and (7) micro-CT imaging which provides state-of-the art multidimensional imaging of the injured lung that is reminiscent of HRCT applied for IPF diagnosis (19).

\section{Limitations}

The past 35 years more than 500 experimental studies have been performed describing therapeutic efficacy of novel compounds in the BLM model. Unfortunately, less than 5\% have applied a therapeutic protocol indicated by drug administration at $>7$ days following BLM challenge $(18,114)$. Even day 7 in most of the experimental models represents a stage of inflammation or early fibrosis, evidence that comes in contrast to the clinical situation in which treatment is initiated after onset of symptoms and when fibrosis has already been established. Intriguingly, pirfenidone and nintedanib received approval to proceed to clinical trials based on preventive protocols or even therapeutic protocols targeting the inflammatory or the early-fibrotic phase of the BLM model (115-117). In addition, most of the therapeutic compounds have been preclinically tested in young animals while it has been clearly shown that aged mice are more susceptible to fibrotic injury (26), which is in accordance with patients with IPF. Importantly, preclinical efficacy of the majority of anti-fibrotic agents was tested in a single model, majorly the BLM-induced model, and based on histologic end points, such as collagen deposition that are not clinically relevant, at least to the extent of lung function tests or survival analysis. Moreover, many of the therapeutic outcomes were subject to evaluation bias considering that most of the preclinical studies were not blinded and the investigator was aware of the animals' treatment. Reproducibility issues arising from different experimental settings between different labs could also account for discrepancies in treatment effects and lack of generalizable results. Finally, it is worth mentioning that animal size needs to be balanced with the statistical power needed to generate robust data and that insufficient reporting of experimental animal data or unpublished negative therapeutic results severely hamper the validity of experimental studies.

\section{Conclusion and Personal View}

An animal model is a simple representation of a complex biology system. Critics focusing on the reasons why an animal model cannot fully reproduce human disease are not helpful and do not elicit a solution. The role of an animal model is to recapitulate specific aspects of a disease. Consequently, animal models should be carefully selected, designed, and conducted in order to bridge translational gaps between bench and bedside. Currently, the BLM model of lung fibrosis represents the cheapest, easiest, fastest, most reproducible, and thus most extensively used animal model of IPF; advantages that overcome the handicap of minimal representation of human disease. So far, it has provided us with invaluable insights into IPF pathogenesis, prognosis, and treatment. We recommend the use of the male aged BLM mouse model as the first-line animal model to test safety and efficacy of a therapeutic compound administered during the stage of established fibrosis. Nevertheless, efficacy preclinical studies should be enriched with two or even three animal models including clinically relevant end points such as lung function mechanics, survival analysis as well as biomarkers (28). Collaboration between veterinary and human clinical researchers must be encouraged in order to establish and solidify a common language, and common diagnostic criteria and nomenclature, thus strengthening the opportunity for advancements toward a cure for lung fibrosis in both animal and humans. Humanization of animal models, spontaneous fibroses animals and application of high-throughput "omics" tools may help us improve the clinical translation in the near future.

\section{AUTHOR CONTRIBUTIONS}

Conception and study oversight: MG, AL, VA, and AT. Drafting manuscript: JT, GR, KW, SJ, and IN. Critical revision of manuscript: MG, AL, VA, and AT. Final approval: all authors. 


\section{ACKNOWLEDGMENTS}

The authors acknowledge the Lester and Sue Smith Foundation, Coalition for Pulmonary Fibrosis, and the Pulmonary Fibrosis Foundation for their support. The authors also acknowledge Amy

\section{REFERENCES}

1. Raghu G, Rochwerg B, Zhang Y, Garcia CA, Azuma A, Behr J, et al. An official ATS/ERS/JRS/ALAT clinical practice guideline: treatment of idiopathic pulmonary fibrosis. An update of the 2011 clinical practice guideline. Am J Respir Crit Care Med (2015) 192(2):e3-19. doi:10.1164/ rccm.201506-1063ST

2. Travis WD, Costabel U, Hansell DM, King TE Jr, Lynch DA, Nicholson AG, et al. An official American Thoracic Society/European Respiratory Society statement: update of the international multidisciplinary classification of the idiopathic interstitial pneumonias. Am J Respir Crit Care Med (2013) 188(6):733-48. doi:10.1164/rccm.201308-1483ST

3. Ryu JH, Moua T, Daniels CE, Hartman TE, Yi ES, Utz JP, et al. Idiopathic pulmonary fibrosis: evolving concepts. Mayo Clin Proc (2014) 89(8):1130-42. doi:10.1016/j.mayocp.2014.03.016

4. Blackwell TS, Tager AM, Borok Z, Moore BB, Schwartz DA, Anstrom KJ, et al. Future directions in idiopathic pulmonary fibrosis research: an NHLBI workshop report. Am J Respir Crit Care Med (2014) 189(2):214-22. doi:10.1164/rccm.201306-1141WS

5. Ahluwalia N, Shea BS, Tager AM. New therapeutic targets in idiopathic pulmonary fibrosis. Aiming to rein in runaway wound-healing responses. Am J Respir Crit Care Med (2014) 190(8):867-78. doi:10.1164/rccm. 201403-0509PP

6. Chilosi M, Carloni A, Rossi A, Poletti V. Premature lung aging and cellular senescence in the pathogenesis of idiopathic pulmonary fibrosis and COPD/ emphysema. Transl Res (2013) 162(3):156-73. doi:10.1016/j.trsl.2013.06.004

7. Tzouvelekis A, Kaminski N. Epigenetics in idiopathic pulmonary fibrosis. Biochem Cell Biol (2015) 93(2):159-70. doi:10.1139/bcb-2014-0126

8. Jones MG, Fletcher S, Richeldi L. Idiopathic pulmonary fibrosis: recent trials and current drug therapy. Respiration (2013) 86(5):353-63. doi:10.1159/ 000356958

9. Raghu G, Chen SY, Yeh WS, Maroni B, Li Q, Lee YC, et al. Idiopathic pulmonary fibrosis in US Medicare beneficiaries aged 65 years and older: incidence, prevalence, and survival, 2001-11. Lancet Respir Med (2014) 2(7):566-72. doi:10.1016/S2213-2600(14)70101-8

10. Spagnolo P, Tzouvelekis A, Maher TM. Personalized medicine in idiopathic pulmonary fibrosis: facts and promises. Curr Opin Pulm Med (2015) 21(5):470-8. doi:10.1097/MCP.0000000000000187

11. Tzouvelekis A, Bonella F, Spagnolo P. Update on therapeutic management of idiopathic pulmonary fibrosis. Ther Clin Risk Manag (2015) 11:359-70. doi:10.2147/TCRM.S69716

12. Tzouvelekis A, Herazo-Maya J, Sakamoto K, Bouros D. Biomarkers in the evaluation and management of idiopathic pulmonary fibrosis. Curr Top Med Chem (2016) 16(14):1587-98. doi:10.2174/1568026616666150930120959

13. Tzouvelekis A, Tzilas V, Papiris S, Aidinis V, Bouros D. Diagnostic and prognostic challenges in Idiopathic Pulmonary Fibrosis: a patient's "Q and A" approach. Pulm Pharmacol Ther (2017) 42:21-24. doi:10.1016/j. pupt.2016.12.002

14. Tzouvelekis A, Yu G, Lino Cardenas C, Herazo-Maya JD, Wang R, Woolard T, et al. SH2 domain-containing phosphatase-2 is a novel antifibrotic regulator in pulmonary fibrosis. Am J Respir Crit Care Med (2017) 195(4):500-514. doi:10.1164/rccm.201602-0329OC

15. King TE Jr, Bradford WZ, Castro-Bernardini S, Fagan EA, Glaspole I, Glassberg MK, et al. A phase 3 trial of pirfenidone in patients with idiopathic pulmonary fibrosis. N Engl J Med (2014) 370(22):2083-92. doi:10.1056/ NEJMoa 1402582

16. Richeldi L, du Bois RM, Raghu G, Azuma A, Brown KK, Costabel U, et al. Efficacy and safety of nintedanib in idiopathic pulmonary fibrosis. $N$ Engl J Med (2014) 370(22):2071-82. doi:10.1056/NEJMoa1402584

17. Bouros D, Tzouvelekis A. Idiopathic pulmonary fibrosis: on the move. Lancet Respir Med (2014) 2(1):17-9. doi:10.1016/S2213-2600(13)70240-6
Miele, BVM\&S MRCVS (University of Edinburgh) for her contributions in providing veterinary histopathology images used in the construction of Table 1. AT is a recipient of a Marie Curie/ Sklodowska ERS/RESPIRE 2 fellowship (8860-2015). All authors have no financial affiliations or conflicts of interest to disclose.

18. Moeller A, Ask K, Warburton D, Gauldie J, Kolb M. The bleomycin animal model: a useful tool to investigate treatment options for idiopathic pulmonary fibrosis? Int J Biochem Cell Biol (2008) 40(3):362-82. doi:10.1016/j. biocel.2007.08.011

19. Mouratis MA, Aidinis V. Modeling pulmonary fibrosis with bleomycin. Curr Opin Pulm Med (2011) 17(5):355-61. doi:10.1097/MCP.0b013e328349ac2b

20. Moore BB, Lawson WE, Oury TD, Sisson TH, Raghavendran K, Hogaboam CM. Animal models of fibrotic lung disease. Am J Respir Cell Mol Biol (2013) 49(2):167-79. doi:10.1165/rcmb.2013-0094TR

21. Moore BB, Hogaboam CM. Murine models of pulmonary fibrosis. Am J Physiol Lung Cell Mol Physiol (2008) 294(2):L152-60. doi:10.1152/ ajplung.00313.2007

22. Organ L, Bacci B, Koumoundouros E, Barcham G, Kimpton W, Nowell CJ, et al. A novel segmental challenge model for bleomycin-induced pulmonary fibrosis in sheep. Exp Lung Res (2015) 41(3):115-34. doi:10.3109/ 01902148.2014 .985806

23. Jenkins RG, Moore BB, Chambers RC, Eickelberg O, Konigshoff M, Kolb M, et al. An official American Thoracic Society workshop report: use of animal models for the preclinical assessment of potential therapies for pulmonary fibrosis. Am J Respir Cell Mol Biol (2017) 56(5):667-79. doi:10.1165/rcmb.2017-0096ST

24. Degryse AL, Tanjore H, Xu XC, Polosukhin VV, Jones BR, McMahon FB, et al. Repetitive intratracheal bleomycin models several features of idiopathic pulmonary fibrosis. Am J Physiol Lung Cell Mol Physiol (2010) 299(4):L442-52. doi:10.1152/ajplung.00026.2010

25. Cai Y, Zhu L, Zhang F, Niu G, Lee S, Kimura S, et al. Noninvasive monitoring of pulmonary fibrosis by targeting matrix metalloproteinases (MMPs). Mol Pharm (2013) 10(6):2237-47. doi:10.1021/mp300613x

26. Sueblinvong V, Neujahr DC, Mills ST, Roser-Page S, Ritzenthaler JD, Guidot D, et al. Predisposition for disrepair in the aged lung. Am J Med Sci (2012) 344(1):41-51. doi:10.1097/MAJ.0b013e318234c132

27. Naik PK, Moore BB. Viral infection and aging as cofactors for the development of pulmonary fibrosis. Expert Rev Respir Med (2010) 4(6):759-71. doi:10.1586/ers.10.73

28. Peng R, Sridhar S, Tyagi G, Phillips JE, Garrido R, Harris P, et al. Bleomycin induces molecular changes directly relevant to idiopathic pulmonary fibrosis: a model for "active" disease. PLoS One (2013) 8(4):e59348. doi:10.1371/ journal.pone. 0059348

29. Izbicki G, Segel MJ, Christensen TG, Conner MW, Breuer R. Time course of bleomycin-induced lung fibrosis. Int J Exp Pathol (2002) 83(3):111-9. doi:10.1046/j.1365-2613.2002.00220.x

30. Stefanov AN, Fox J, Depault F, Haston CK. Positional cloning reveals strain-dependent expression of Trim16 to alter susceptibility to bleomycin-induced pulmonary fibrosis in mice. PLoS Genet (2013) 9(1):e1003203. doi:10.1371/journal.pgen.1003203

31. Hoyt DG, Lazo JS. Alterations in pulmonary mRNA encoding procollagens, fibronectin and transforming growth factor-beta precede bleomycininduced pulmonary fibrosis in mice. J Pharmacol Exp Ther (1988) 246(2): $765-71$.

32. Aguilar S, Scotton CJ, McNulty K, Nye E, Stamp G, Laurent G, et al. Bone marrow stem cells expressing keratinocyte growth factor via an inducible lentivirus protects against bleomycin-induced pulmonary fibrosis. PLoS One (2009) 4(11):e8013. doi:10.1371/journal.pone.0008013

33. Redente EF, Jacobsen KM, Solomon JJ, Lara AR, Faubel S, Keith RC, et al. Age and sex dimorphisms contribute to the severity of bleomycin-induced lung injury and fibrosis. Am J Physiol Lung Cell Mol Physiol (2011) 301(4):L510-8. doi:10.1152/ajplung.00122.2011

34. Chung MP, Monick MM, Hamzeh NY, Butler NS, Powers LS, Hunninghake GW. Role of repeated lung injury and genetic background in bleomycin-induced fibrosis. Am J Respir Cell Mol Biol (2003) 29(3 Pt 1): 375-80. doi:10.1165/rcmb.2003-0029OC 
35. Ortiz LA, Gambelli F, McBride C, Gaupp D, Baddoo M, Kaminski N, et al. Mesenchymal stem cell engraftment in lung is enhanced in response to bleomycin exposure and ameliorates its fibrotic effects. Proc Natl Acad Sci U S A (2003) 100(14):8407-11. doi:10.1073/pnas.1432929100

36. Rojas M, Xu J, Woods CR, Mora AL, Spears W, Roman J, et al. Bone marrow-derived mesenchymal stem cells in repair of the injured lung. Am J Respir Cell Mol Biol (2005) 33(2):145-52. doi:10.1165/rcmb.2004-0330OC

37. Ortiz LA, Dutreil M, Fattman C, Pandey AC, Torres G, Go K, et al. Interleukin 1 receptor antagonist mediates the antiinflammatory and antifibrotic effect of mesenchymal stem cells during lung injury. Proc Natl Acad Sci U S A (2007) 104(26):11002-7. doi:10.1073/pnas.0704421104

38. Foskett AM, Bazhanov N, Ti X, Tiblow A, Bartosh TJ, Prockop DJ. Phase-directed therapy: TSG-6 targeted to early inflammation improves bleomycin-injured lungs. Am JPhysiol Lung Cell Mol Physiol (2014) 306(2):L120-31. doi:10.1152/ajplung.00240.2013

39. Hecker L, Logsdon NJ, Kurundkar D, Kurundkar A, Bernard K, Hock T, et al. Reversal of persistent fibrosis in aging by targeting Nox4-Nrf2 redox imbalance. Sci Transl Med (2014) 6(231):231ra47. doi:10.1126/ scitranslmed.3008182

40. Srour N, Thebaud B. Mesenchymal stromal cells in animal bleomycin pulmonary fibrosis models: a systematic review. Stem Cells Transl Med (2015) 4(12):1500-10. doi:10.5966/sctm.2015-0121

41. Cross J, Stenton GR, Harwig C, Szabo C, Genovese T, Di Paola R, et al. AQX-1125, a small molecule SHIP1 activator, inhibits bleomycin-induced pulmonary fibrosis. Br J Pharmacol (2017). doi:10.1111/ bph.13934

42. Tanaka KI, Niino T, Ishihara T, Takafuji A, Takayama T, Kanda Y, et al. Protective and therapeutic effect of felodipine against bleomycin-induced pulmonary fibrosis in mice. Sci Rep (2017) 7(1):3439. doi:10.1038/ s41598-017-03676-y

43. Lee SH, Lee EJ, Lee SY, Kim JH, Shim JJ, Shin C, et al. The effect of adipose stem cell therapy on pulmonary fibrosis induced by repetitive intratracheal bleomycin in mice. Exp Lung Res (2014) 40(3):117-25. doi:10.3109/01902148. 2014.881930

44. Moodley Y, Vaghjiani V, Chan J, Baltic S, Ryan M, Tchongue J, et al. Anti-inflammatory effects of adult stem cells in sustained lung injury: a comparative study. PLoS One (2013) 8(8):e69299. doi:10.1371/journal. pone.0069299

45. Davis GS, Leslie KO, Hemenway DR. Silicosis in mice: effects of dose, time, and genetic strain. J Environ Pathol Toxicol Oncol (1998) 17(2):81-97.

46. Davis GS, Pfeiffer LM, Hemenway DR. Interferon-gamma production by specific lung lymphocyte phenotypes in silicosis in mice. Am J Respir Cell Mol Biol (2000) 22(4):491-501. doi:10.1165/ajrcmb.22.4.3599

47. Antonini JM, Hemenway DR, Davis GS. Quantitative image analysis of lung connective tissue in murine silicosis. Exp Lung Res (2000) 26(2):71-88. doi:10.1080/019021400269880

48. Davis GS, Pfeiffer LM, Hemenway DR. Expansion of interferon-gammaproducing lung lymphocytes in mouse silicosis. Am J Respir Cell Mol Biol (1999) 20(4):813-24. doi:10.1165/ajrcmb.20.4.3407

49. Davis GS, Pfeiffer LM, Hemenway DR. Persistent overexpression of interleukin-1beta and tumor necrosis factor-alpha in murine silicosis. J Environ Pathol Toxicol Oncol (1998) 17(2):99-114.

50. Lakatos HF, Burgess HA, Thatcher TH, Redonnet MR, Hernady E, Williams JP, et al. Oropharyngeal aspiration of a silica suspension produces a superior model of silicosis in the mouse when compared to intratracheal instillation. Exp Lung Res (2006) 32(5):181-99. doi:10.1080/ 01902140600817465

51. Barbarin V, Arras M, Misson P, Delos M, McGarry B, Phan SH, et al. Characterization of the effect of interleukin-10 on silica-induced lung fibrosis in mice. Am J Respir Cell Mol Biol (2004) 31(1):78-85. doi:10.1165/ rcmb.2003-02990C

52. Barbarin V, Xing Z, Delos M, Lison D, Huaux F. Pulmonary overexpression of IL-10 augments lung fibrosis and Th2 responses induced by silica particles. Am J Physiol Lung Cell Mol Physiol (2005) 288(5):L841-8. doi:10.1152/ ajplung.00329.2004

53. Davis GS, Holmes CE, Pfeiffer LM, Hemenway DR. Lymphocytes, lymphokines, and silicosis. JEnviron Pathol Toxicol Oncol (2001) 20(Suppl 1): 53-65. doi:10.1615/JEnvironPatholToxicolOncol.v20.iSuppl.1.50
54. Misson P, van den Brule S, Barbarin V, Lison D, Huaux F. Markers of macrophage differentiation in experimental silicosis. J Leukoc Biol (2004) 76(5):926-32. doi:10.1189/jlb.0104019

55. Baur X, Woitowitz HJ, Budnik LT, Egilman D, Oliver C, Frank A, et al. Asbestos, asbestosis, and cancer: the Helsinki criteria for diagnosis and attribution. Critical need for revision of the 2014 update. Am J Ind Med (2017) 60(5):411-21. doi:10.1002/ajim.22709

56. Roggli V, Gibbs AR, Attanoos R, Churg A, Popper H, Corrin B, et al. Pathology of asbestosis: an update of the diagnostic criteria response to a critique. Arch Pathol Lab Med (2016) 140(9):950-2. doi:10.5858/arpa.20150503-SA

57. Kim SJ, Cheresh P, Jablonski RP, Williams DB, Kamp DW. The role of mitochondrial DNA in mediating alveolar epithelial cell apoptosis and pulmonary fibrosis. Int J Mol Sci (2015) 16(9):21486-519. doi:10.3390/ ijms 160921486

58. Cyphert JM, Padilla-Carlin DJ, Schladweiler MC, Shannahan JH, Nyska A, Kodavanti UP, et al. Long-term response of rats to single intratracheal exposure of Libby amphibole or amosite. J Toxicol Environ Health A (2012) 75(3):183-200. doi:10.1080/15287394.2012.641203

59. Rasmussen DL, Pfau JC. Asbestos activates CH12.LX B-lymphocytes via macrophage signaling. J Immunotoxicol (2012) 9(2):129-40. doi:10.3109/ 1547691X.2011.631953

60. Padilla-Carlin DJ, Schladweiler MC, Shannahan JH, Kodavanti UP, Nyska A, Burgoon LD, et al. Pulmonary inflammatory and fibrotic responses in Fischer 344 rats after intratracheal instillation exposure to Libby amphibole. J Toxicol Environ Health A (2011) 74(17):1111-32. doi:10.1080/ 15287394.2011.586940

61. Li J, Poovey HG, Rodriguez JF, Brody A, Hoyle GW. Effect of platelet-derived growth factor on the development and persistence of asbestos-induced fibroproliferative lung disease. JEnviron Pathol Toxicol Oncol (2004) 23(4):253-66. doi:10.1615/JEnvPathToxOncol.v23.i4.20

62. Selman M, Buendia-Roldan I, Pardo A. Aging and pulmonary fibrosis. Rev Invest Clin (2016) 68(2):75-83.

63. Meiners S, Eickelberg O, Konigshoff M. Hallmarks of the ageing lung. Eur Respir J (2015) 45(3):807-27. doi:10.1183/09031936.00186914

64. Thannickal VJ, Murthy M, Balch WE, Chandel NS, Meiners S, Eickelberg O, et al. Blue journal conference. Aging and susceptibility to lung disease. Am J Respir Crit Care Med (2015) 191(3):261-9. doi:10.1164/ rccm.201410-1876PP

65. Englert JM, Hanford LE, Kaminski N, Tobolewski JM, Tan RJ, Fattman CL, et al. A role for the receptor for advanced glycation end products in idiopathic pulmonary fibrosis. Am J Pathol (2008) 172(3):583-91. doi:10.2353/ ajpath.2008.070569

66. Samuel CS, Zhao C, Bond CP, Hewitson TD, Amento EP, Summers RJ. Relaxin1-deficient mice develop an age-related progression of renal fibrosis. Kidney Int (2004) 65(6):2054-64. doi:10.1111/j.1523-1755.2004.00628.x

67. Samuel CS, Zhao C, Bathgate RA, Bond CP, Burton MD, Parry LJ, et al. Relaxin deficiency in mice is associated with an age-related progression of pulmonary fibrosis. FASEB J (2003) 17(1):121-3. doi:10.1096/fj.02-0449fje

68. Naik PN, Horowitz JC, Moore TA, Wilke CA, Toews GB, Moore BB. Pulmonary fibrosis induced by gamma-herpesvirus in aged mice is associated with increased fibroblast responsiveness to transforming growth factor-beta. J Gerontol A Biol Sci Med Sci (2012) 67(7):714-25. doi:10.1093/gerona/glr211

69. Torres-Gonzalez E, Bueno M, Tanaka A, Krug LT, Cheng DS, Polosukhin VV, et al. Role of endoplasmic reticulum stress in age-related susceptibility to lung fibrosis. Am J Respir Cell Mol Biol (2012) 46(6):748-56. doi:10.1165/rcmb.2011-0224OC

70. Egan JJ, Adamali HI, Lok SS, Stewart JP, Woodcock AA. Ganciclovir antiviral therapy in advanced idiopathic pulmonary fibrosis: an open pilot study. Pulm Med (2011) 2011:240805. doi:10.1155/2011/240805

71. Sime PJ, Xing Z, Graham FL, Csaky KG, Gauldie J. Adenovector-mediated gene transfer of active transforming growth factor-betal induces prolonged severe fibrosis in rat lung. J Clin Invest (1997) 100(4):768-76. doi:10.1172/ JCI119590

72. Lee CG, Kang HR, Homer RJ, Chupp G, Elias JA. Transgenic modeling of transforming growth factor-beta(1): role of apoptosis in fibrosis and alveolar remodeling. Proc Am Thorac Soc (2006) 3(5):418-23. doi:10.1513/ pats.200602-017AW 
73. Vicencio AG, Lee CG, Cho SJ, Eickelberg O, Chuu Y, Haddad GG, et al. Conditional overexpression of bioactive transforming growth factor-betal in neonatal mouse lung: a new model for bronchopulmonary dysplasia? Am JRespir Cell Mol Biol (2004) 31(6):650-6. doi:10.1165/rcmb.20040092OC

74. Lee CG, Cho SJ, Kang MJ, Chapoval SP, Lee PJ, Noble PW, et al. Early growth response gene 1-mediated apoptosis is essential for transforming growth factor beta1-induced pulmonary fibrosis. J Exp Med (2004) 200(3):377-89. doi:10.1084/jem.20040104

75. Kolb M, Margetts PJ, Anthony DC, Pitossi F, Gauldie J. Transient expression of IL-1beta induces acute lung injury and chronic repair leading to pulmonary fibrosis. J Clin Invest (2001) 107(12):1529-36. doi:10.1172/ JCI12568

76. Sime PJ, Marr RA, Gauldie D, Xing Z, Hewlett BR, Graham FL, et al. Transfer of tumor necrosis factor-alpha to rat lung induces severe pulmonary inflammation and patchy interstitial fibrogenesis with induction of transforming growth factor-betal and myofibroblasts. Am J Pathol (1998) 153(3):825-32. doi:10.1016/S0002-9440(10)65624-6

77. Xing Z, Tremblay GM, Sime PJ, Gauldie J. Overexpression of granulocytemacrophage colony-stimulating factor induces pulmonary granulation tissue formation and fibrosis by induction of transforming growth factorbeta 1 and myofibroblast accumulation. Am J Pathol (1997) 150(1): 59-66.

78. Lee CG, Homer RJ, Zhu Z, Lanone S, Wang X, Koteliansky V, et al. Interleukin-13 induces tissue fibrosis by selectively stimulating and activating transforming growth factor beta(1). J Exp Med (2001) 194(6):809-21. doi:10.1084/jem.194.6.809

79. Roberts SN, Howie SE, Wallace WA, Brown DM, Lamb D, Ramage EA, et al. A novel model for human interstitial lung disease: hapten-driven lung fibrosis in rodents. J Pathol (1995) 176(3):309-18. doi:10.1002/path. 1711760313

80. Christensen PJ, Goodman RE, Pastoriza L, Moore B, Toews GB. Induction of lung fibrosis in the mouse by intratracheal instillation of fluorescein isothiocyanate is not T-cell-dependent. Am J Pathol (1999) 155(5):1773-9. doi:10.1016/S0002-9440(10)65493-4

81. Moore BB, Paine R III, Christensen PJ, Moore TA, Sitterding S, Ngan R, et al. Protection from pulmonary fibrosis in the absence of CCR2 signaling. J Immunol (2001) 167(8):4368-77. doi:10.4049/jimmunol.167.8.4368

82. Karvonen RL, Fernandez-Madrid F, Maughan RL, Palmer KC, FernandezMadrid I. An animal model of pulmonary radiation fibrosis with biochemical, physiologic, immunologic, and morphologic observations. Radiat Res (1987) 111(1):68-80. doi:10.2307/3577022

83. Paun A, Haston CK. Genomic and genome-wide association of susceptibility to radiation-induced fibrotic lung disease in mice. Radiother Oncol (2012) 105(3):350-7. doi:10.1016/j.radonc.2012.08.004

84. Haston CK. Mouse genetic approaches applied to the normal tissue radiation response. Front Oncol (2012) 2:94. doi:10.3389/fonc.2012.00094

85. Paun A, Fox J, Balloy V, Chignard M, Qureshi ST, Haston CK. Combined Tlr2 and Tlr4 deficiency increases radiation-induced pulmonary fibrosis in mice. Int J Radiat Oncol Biol Phys (2010) 77(4):1198-205. doi:10.1016/j. ijrobp.2009.12.065

86. Haston CK, Travis EL. Murine susceptibility to radiation-induced pulmonary fibrosis is influenced by a genetic factor implicated in susceptibility to bleomycin-induced pulmonary fibrosis. Cancer Res (1997) 57(23): 5286-91.

87. Haston CK, Amos CI, King TM, Travis EL. Inheritance of susceptibility to bleomycin-induced pulmonary fibrosis in the mouse. Cancer Res (1996) 56(11):2596-601.

88. Naikawadi RP, Disayabutr S, Mallavia B, Donne ML, Green G, La JL, et al. Telomere dysfunction in alveolar epithelial cells causes lung remodeling and fibrosis. JCI Insight (2016) 1(14):e86704. doi:10.1172/jci.insight.86704

89. Povedano JM, Martinez P, Flores JM, Mulero F, Blasco MA. Mice with pulmonary fibrosis driven by telomere dysfunction. Cell Rep (2015) 12(2):286-99. doi:10.1016/j.celrep.2015.06.028

90. Armanios M. Telomerase and idiopathic pulmonary fibrosis. Mutat Res (2012) 730(1-2):52-8. doi:10.1016/j.mrfmmm.2011.10.013

91. Driscoll B, Buckley S, Bui KC, Anderson KD, Warburton D. Telomerase in alveolar epithelial development and repair. Am J Physiol Lung Cell Mol Physiol (2000) 279(6):L1191-8.
92. Kim JK, Lim Y, Kim KA, Seo MS, Kim JD, Lee KH, et al. Activation of telomerase by silica in rat lung. Toxicol Lett (2000) 111(3):263-70. doi:10.1016/ S0378-4274(99)00195-2

93. Liu T, Chung MJ, Ullenbruch M, Yu H, Jin H, Hu B, et al. Telomerase activity is required for bleomycin-induced pulmonary fibrosis in mice. J Clin Invest (2007) 117(12):3800-9. doi:10.1172/JCI32369

94. Degryse AL, Xu XC, Newman JL, Mitchell DB, Tanjore H, Polosukhin VV, et al. Telomerase deficiency does not alter bleomycin-induced fibrosis in mice. Exp Lung Res (2012) 38(3):124-34. doi:10.3109/01902148.2012.658148

95. Nogee LM, Dunbar AE III, Wert S, Askin F, Hamvas A, Whitsett JA. Mutations in the surfactant protein $\mathrm{C}$ gene associated with interstitial lung disease. Chest (2002) 121(3 Suppl):20S-1S. doi:10.1378/chest.121.3_suppl.20S

96. Nogee LM, Dunbar AE III, Wert SE, Askin F, Hamvas A, Whitsett JA. A mutation in the surfactant protein $\mathrm{C}$ gene associated with familial interstitial lung disease. N Engl J Med (2001) 344(8):573-9. doi:10.1056/ NEJM200102223440805

97. Glasser SW, Detmer EA, Ikegami M, Na CL, Stahlman MT, Whitsett JA. Pneumonitis and emphysema in sp-C gene targeted mice. J Biol Chem (2003) 278(16):14291-8. doi:10.1074/jbc.M210909200

98. Pierce EM, Carpenter K, Jakubzick C, Kunkel SL, Flaherty KR, Martinez FJ, et al. Therapeutic targeting of CC ligand 21 or CC chemokine receptor 7 abrogates pulmonary fibrosis induced by the adoptive transfer of human pulmonary fibroblasts to immunodeficient mice. Am JPathol (2007) 170(4):1152-64. doi:10.2353/ajpath.2007.060649

99. Trujillo G, Meneghin A, Flaherty KR, Sholl LM, Myers JL, Kazerooni EA, et al. TLR9 differentiates rapidly from slowly progressing forms of idiopathic pulmonary fibrosis. Sci Transl Med (2010) 2(57):57ra82. doi:10.1126/ scitranslmed.3001510

100. Fujii H, Luo ZJ, Kim HJ, Newbigging S, Gassas A, Keating A, et al. Humanized chronic graft-versus-host disease in NOD-SCID il2rgamma-/- (NSG) mice with G-CSF-mobilized peripheral blood mononuclear cells following cyclophosphamide and total body irradiation. PLoS One (2015) 10(7):e0133216. doi:10.1371/journal.pone.0133216

101. Shultz LD, Ishikawa F, Greiner DL. Humanized mice in translational biomedical research. Nat Rev Immunol (2007) 7(2):118-30. doi:10.1038/ nri2017

102. Roman J, Brown KK, Olson A, Corcoran BM, Williams KJ; ATS Comparative Biology of Lung Fibrosis Working Group. An official American thoracic society workshop report: comparative pathobiology of fibrosing lung disorders in humans and domestic animals. Ann Am Thorac Soc (2013) 10(6):S224-9. doi:10.1513/AnnalsATS.201309-321ST

103. Williams KJ, Maes R, Del Piero F, Lim A, Wise A, Bolin DC, et al. Equine multinodular pulmonary fibrosis: a newly recognized herpesvirusassociated fibrotic lung disease. Vet Pathol (2007) 44(6):849-62. doi:10.1354/ vp.44-6-849

104. Norris AJ, Naydan DK, Wilson DW. Interstitial lung disease in West Highland White Terriers. Vet Pathol (2005) 42(1):35-41. doi:10.1354/vp. 42-1-35

105. Miele A, Dhaliwal K, Du Toit N, Murchison JT, Dhaliwal C, Brooks H, et al. Chronic pleuropulmonary fibrosis and elastosis of aged donkeys: similarities to human pleuroparenchymal fibroelastosis. Chest (2014) 145(6):1325-32. doi:10.1378/chest.13-1306

106. Wong DM, Belgrave RL, Williams KJ, Del Piero F, Alcott CJ, Bolin SR, et al Multinodular pulmonary fibrosis in five horses. J Am Vet Med Assoc (2008) 232(6):898-905. doi:10.2460/javma.232.6.898

107. Mercer PF, Abbott-Banner K, Adcock IM, Knowles RG. Translational models of lung disease. Clin Sci (2015) 128(4):235-56. doi:10.1042/CS20140373

108. Raghu G, Collard HR, Egan JJ, Martinez FJ, Behr J, Brown KK, et al. An official ATS/ERS/JRS/ALAT statement: idiopathic pulmonary fibrosis: evidence-based guidelines for diagnosis and management. Am J Respir Crit Care Med (2011) 183(6):788-824. doi:10.1164/rccm.2009-040GL

109. Syrjä P, Heikkilä HP, Lilja-Maula L, Krafft E, Clercx C, Day MJ, et al. The histopathology of idiopathic pulmonary fibrosis in West Highland White Terriers shares features of both non-specific interstitial pneumonia and usual interstitial pneumonia in man. J Comp Pathol (2013) 149(2):303-13. doi:10.1016/j.jcpa.2013.03.006

110. Thierry F, Handel I, Hammond G, King LG, Corcoran BM, Schwarz T. Further characterization of computed tomographic and clinical features for staging and prognosis of idiopathic pulmonary fibrosis in West Highland 
White Terriers. Vet Radiol Ultrasound (2017) 58(4):381-8. doi:10.1111/ vru. 12491

111. Williams KJ, Robinson NE, Lim A, Brandenberger C, Maes R, Behan A, et al. Experimental induction of pulmonary fibrosis in horses with the gammaherpesvirus equine herpesvirus 5. PLoS One (2013) 8(10):e77754. doi:10.1371/ journal.pone.0077754

112. Williams K, Malarkey D, Cohn L, Patrick D, Dye J, Toews G. Identification of spontaneous feline idiopathic pulmonary fibrosis: morphology and ultrastructural evidence for a type II pneumocyte defect. Chest (2004) 125(6):2278-88. doi:10.1378/chest.125.6.2278

113. Back H, Ullman K, Leijon M, Soderlund R, Penell J, Stahl K, et al. Genetic variation and dynamics of infections of equid herpesvirus 5 in individual horses. J Gen Virol (2016) 97(1):169-78. doi:10.1099/jgv.0. 000332

114. Antoniu SA, Kolb MR. Update on models of pulmonary fibrosis therapy for preclinical drug research. Expert Opin Drug Discov (2009) 4(9):939-46. doi:10.1517/17460440903186100

115. Schaefer CJ, Ruhrmund DW, Pan L, Seiwert SD, Kossen K. Antifibrotic activities of pirfenidone in animal models. Eur Respir Rev (2011) 20(120):85-97. doi:10.1183/09059180.00001111
116. Huang J, Beyer C, Palumbo-Zerr K, Zhang Y, Ramming A, Distler A, et al. Nintedanib inhibits fibroblast activation and ameliorates fibrosis in preclinical models of systemic sclerosis. Ann Rheum Dis (2016) 75(5):883-90. doi:10.1136/annrheumdis-2014-207109

117. Wollin L, Maillet I, Quesniaux V, Holweg A, Ryffel B. Antifibrotic and anti-inflammatory activity of the tyrosine kinase inhibitor nintedanib in experimental models of lung fibrosis. JPharmacol Exp Ther (2014) 349(2):209-20. doi:10.1124/jpet.113.208223

Conflict of Interest Statement: The authors declare that the research was conducted in the absence of any commercial or financial relationships that could be construed as a potential conflict of interest.

Copyright (๑) 2017 Tashiro, Rubio, Limper, Williams, Elliot, Ninou, Aidinis, Tzouvelekis and Glassberg. This is an open-access article distributed under the terms of the Creative Commons Attribution License (CC BY). The use, distribution or reproduction in other forums is permitted, provided the original author(s) or licensor are credited and that the original publication in this journal is cited, in accordance with accepted academic practice. No use, distribution or reproduction is permitted which does not comply with these terms. 